\title{
Retour sur Le Savant et le Populaire
}

Back to Le Savant et le Populaire

Reflexionando sobre El Sabio y el Popular

Dominique Pasquier

\section{(2) OpenEdition}

\section{Journals}

Édition électronique

URL : http://journals.openedition.org/bssg/143

DOI : $10.4000 /$ bssg. 143

ISSN : 2490-9424

Éditeur

Presses universitaires de Vincennes

Référence électronique

Dominique Pasquier, "Retour sur Le Savant et le Populaire », Biens Symboliques / Symbolic Goods [En ligne], 1 | 2017, mis en ligne le 15 octobre 2017, consulté le 04 mars 2021. URL : http:// journals.openedition.org/bssg/143; DOI : https://doi.org/10.4000/bssg.143 

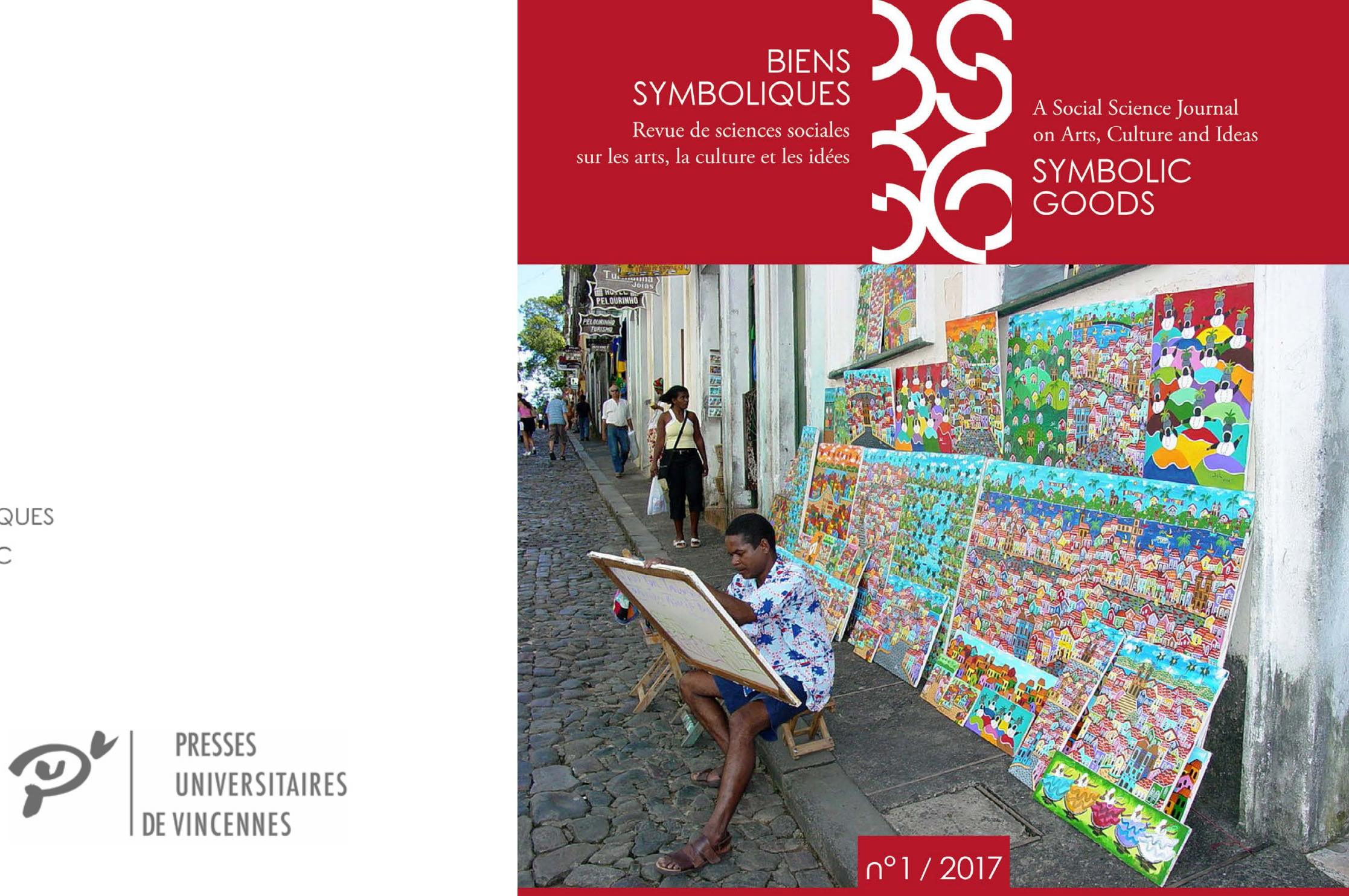

\section{Artistes ordinaires \\ Ordinary Artists}


Retour sur Le Savant et le Populaire

Dominique Pasquier

La fin des années 1970 a été une période très particulière pour la sociologie de la culture française. Je vais me permettre de raconter ces moments de façon personnelle. J'étais alors en thèse à l'EHESS sous la direction de Raymonde Moulin au sein du Centre européen de sociologie historique, laboratoire dirigé par Raymond Aron. Ma thèse portait sur l'œuvre photographique de Lewis Carroll, et j'étais, de ce fait, insérée dans le petit groupe de doctorants et chercheurs qui travaillaient, au sein de ce laboratoire, sur les questions de culture et d'art - ce groupe donnera d'ailleurs naissance quelques années plus tard, en 1983, au Centre de sociologie des arts. Aujourd'hui où les livres de sciences sociales suscitent au mieux une attention courtoise, il est difficile d'imaginer l'incroyable événement médiatique qu'a constitué en 1979 la publication de La Distinction ${ }^{1}$. Bourdieu était très connu depuis ses travaux sur l'école avec Passeron, l'ouvrage était particulièrement innovant sur le plan iconographique et éditorial, et surtout il défendait une théorie du classement social par les classements culturels aussi radicale que l'avaient été les thèses sur la reproduction scolaire, soutenues quinze ans auparavant dans Les Héritiers.

Dans mon laboratoire, le succès de La Distinction n'est pas allé sans poser problème. II y avait certes des conflits de

1 Sur l'impact de la publication de La Distinction en France puis à l'étranger, voir Coulangeon et Duval $2013: 10-15$. personnes. La rupture avec Bourdieu en 1968 avait entraîné Aron à quitter le Centre de sociologie européenne pour créer son propre centre, emmenant avec lui plusieurs chercheurs dont une de ses anciennes thésardes, Raymonde Moulin. À la fin des années 1970, l'animosité entre ces deux laboratoires était moins vive - on peut renvoyer pour le rappel de ces conflits à la description qu'en fait Dominique Schnapper (Busino 2006) - mais elle n'était pas éteinte.

Il y avait aussi et surtout des conflits d'idées. Raymonde Moulin avait publié en 1971 dans la Revue française de sociologie un compte rendu très enthousiaste de La Culture du pauvre de Hoggart (1970a). C'est un ouvrage, écrit-elle, « qui renvoie dos à dos les stéréotypes, symétriques et complémentaires, de l'aristocratisme et du populisme » (Moulin $1971:$ 257) et témoigne d'un " refus de l'ethnocentrisme de l'intellectuel qui, en tant que détenteur monopoliste de la définition de la culture, est porté à caractériser négativement, par la dépossession, les classes populaires » (258). On peut lire dans ces lignes un positionnement clair du côté des attaques à venir de Grignon et Passeron dans Le Savant et le Populaire à propos du traitement que fait Bourdieu dans La Distinction de « la culture du pauvre comme culture plus pauvre » : « Tout se passe comme si l'observateur, placé sur la pointe de la pyramide sociale, perdait son pouvoir de discernement à mesure que son regard plonge vers la base 
de celle-ci : la raréfaction de l'information pertinente va de pair avec l'indifférence aux variations et aux oppositions dont la connaissance permettrait seule de construire l'espace social des goûts populaires » (Grignon \& Passeron 1989 : 115).

De fait, Raymonde Moulin et Jean-Claude Passeron étaient très proches. Passeron avait participé de près à la grande enquête nationale sur les artistes plasticiens du Centre de sociologie de l'art (Moulin, Passeron, Pasquier, Porto Vazquez 1985), puis co-organisé le colloque « Sociologie de l'art » en 1985 à la Vieille Charité à Marseille où il dirigeait désormais le SHADyC, et dont les actes ont été publiés l'année suivante (Moulin 1986). Mais surtout, il avait poursuivi, avec de nombreux textes et un colloque consacré à Hoggart (Passeron 1999) son travail de relecture et de diffusion de cette œuvre, créant une alternative forte à la domination intellectuelle des théories de La Distinction sur les débats en sociologie de la culture en France. La traduction de 33 Newport Street par Grignon en 1991 viendra compléter ces apports.

L'autre ouverture est venue d'Howard Becker. Pendant qu'il écrivait Les Mondes de l'art (Becker 1988), il avait lu les travaux de Raymonde Moulin sur le marché de l'art et lui avait écrit. Elle l'avait fait venir en France comme professeur invité à I'EHESS puis, à sa suite, avait invité d'autres chercheurs interactionnistes qui travaillaient sur des questions de culture, dont Fred Davis. II y a donc eu dans ce centre, au début des années 1980, une ouverture sur des horizons intellectuels très différents des perspectives bourdieusiennes sur la culture. Je mesure, avec le recul, tout ce que cela m'a apporté de liberté : sans la double inspiration Hoggart/Becker je n'aurais jamais pu aborder avec la sérénité nécessaire un matériau comme celui des courriers de fans adressés aux vedettes d'une série de télévision bas de gamme (Pasquier 1989). Si j'avais regardé « de haut » ces courriers d'enfants issus des milieux populaires, j'y aurais certainement vu culture dégradée et mystification télévisuelle. Mais Hoggart m'avait appris à chercher ce qui fait sens par rapport à la vie de ceux qu'on étudie et Becker à traiter la télévision comme un objet de recherche tout aussi important que la culture cultivée.

Est-ce que Le Savant et le Populaire, et plus largement les travaux de Grignon et Passeron, permettent de résoudre les problèmes de tension entre misérabilisme et populisme qu'ils ont analysés ? Non, mais ils constituent une mise en garde de tous les instants, à bien des égards essentielle.

Je coordonne aujourd'hui une recherche sur l'appropriation d'Internet en milieu rural par des individus peu ou pas diplômés ${ }^{2}$. On sait en effet peu de choses sur la spécificité du rapport au numérique dans les milieux populaires. II existe de nombreux travaux sur les classes populaires mais ils ne s'intéressent qu'à la marge aux pratiques de loisirs et de communication. II existe aussi de nombreux travaux sur les usages du numérique mais, sauf rares exceptions, ils s'intéressent prioritairement aux usages innovants des jeunes urbains diplômés.

Cette recherche est directement inspirée par des problématiques hoggartiennes. Nous nous sommes éloignés des analyses en termes de manque et d'absence, pour partir au contraire du principe que l'appropriation de la culture ne peut « être dissociée des conditions sociales où elle

2 POPLOG, Logiques numériques en milieu populaire (projet ANR 14-CE290007). 
s'accomplit et par là de l'ethos qui caractérise en propre un groupe social » (Passeron in Hoggart 1970a : 22). Dans un texte des années 1970, Hoggart s'est interrogé sur l'impact de deux innovations sur les foyers ouvriers : la télévision et l'automobile (Hoggart 1970b). La première a tout de suite exercé une fonction de rassemblement du groupe familial au sein du foyer, explique-t-il. L'automobile constituait a contrario une menace sur la cohésion familiale en permettant de connaître d'autres régions (areas) et d'autres styles de vie. Or, constate Hoggart, les ouvriers en ont un usage - dont se moquent souvent les classes moyennes et supérieures qui leur permet de neutraliser son caractère potentiellement destructeur pour la vie familiale. Lorsqu'ils partent en voiture à la campagne ou au bord de la mer, ils n'en profitent pas toujours pour aller se baigner ou marcher, et restent tous ensemble dans leur voiture, avec de la nourriture, des journaux et la radio : ils font de l'automobile a mobile living room (Hoggart 1970b : 54). Il en va d'Internet comme il en va de l'automobile. A priori, c'est un outil qui permet, de façon individualisée, de poursuivre depuis chez soi, des échanges avec des interlocuteurs extérieurs au foyer et d'accéder à toutes sortes de contenus. C'est donc un outil menaçant pour la cohésion familiale. Mais si je prends l'exemple de la transformation des sociabilités familiales dans la partie de notre enquête consacrée à des femmes employées dans le secteur du service à la personne (aides soignantes, aides à domicile en milieu rural, auxiliaires de vie), on voit que les foyers populaires étudiés ont cherché à mettre en place plusieurs tactiques pour préserver l'unité du collectif familial : ces familles appliquent un principe de transparence sur les activités en ligne (entre parents et enfants, mais aussi au sein du couple), ils multiplient les appropriations collectives des outils (adresse mail commune aux deux conjoints par exemple) et maintiennent étanches les frontières entre vie privée et vie professionnelle (contrairement au brouillage de cette frontière, largement étudié dans le cas des cadres). Les nouveaux moyens de communication sont aussi exploités dans les relations familiales hors foyer : les textos avec les parents âgés se cumulent aux visites de face à face dans un double objectif de réassurance et de témoignage de la force du lien ; Facebook permet de garder le contact une ou deux fois par an avec des tantes ou des cousines que l'on ne voit plus assez pour avoir envie de leur téléphoner ; Skype offre des moments de présence à distance pour passer une soirée ou un dîner avec la famille restée dans le pays d'origine, etc. C'est en s'intéressant à ces détails de la vie de tous les jours que l'on peut comprendre les transformations introduites par Internet dans des foyers populaires, mais aussi, et peut-être surtout, les limites que les individus cherchent à mettre à ces transformations. Comme nous y invite Le Savant et le Populaire, c'est en renouant avec un impératif de description empirique fin, sensible aux variations et aux nuances, que peut s'esquisser une sociologie des classes populaires.

Dominique Pasquier CNRS UMR 9217 Institut interdisciplinaire de l'innovation (i3) http://www.i-3.fr/ 


\section{Références bibliographiques}

ARON Raymond (1983). Mémoires. Paris, Julliard.

BAKHTINE Mikhaïl (1970). L'CEuvre de François Rabelais et la culture populaire au Moyen Âge et sous la Renaissance. Paris, Gallimard.

BECKER Howard (1988). Les Mondes de l'art. Traduit de l'anglais par Jeanne Bouniort. Paris, Flammarion.

Bellavance Guy, Boivin Micheline, Santerre Lise (dir.) (2000). Démocratisation de la culture ou démocratie culturelle ? Deux logiques d'action publique. Québec, Éditions de l'IQRC.

Boıs Géraldine (2008). " Le consentement à la domination littéraire. Degrés et diversité de ses formes chez les écrivains "les moins reconnus" de l'univers littéraire ». Tracés, $14: 55-76$.

BOURDIEU Pierre (1979). La Distinction. Critique sociale du jugement. Paris, Minuit.

Bourdieu Pierre (1984). Questions de sociologie. Paris, Minuit.

BOURDIEU Pierre (1988). « Entretien recueilli par Beate Krais ». In BOURDIEU Pierre, Chamboredon Jean-Claude, PAsseron Jean-Claude, Le Métier de sociologue. Préalables épistémologiques. Paris, Éditions de l'EHESS (cinquième édition)

BouRdieu Pierre (1989). La Noblesse d'État. Paris, Minuit.

BOURDIEU Pierre (1993). «Les contradictions de l'héritage ». In Bourdieu Pierre (dir.), La Misère du monde. Paris, Seuil : 711-718.

BOURDIEU Pierre (1998) [1992]. Les Règles de l'art. Genèse et structure du champ littéraire. Paris, Seuil.

BouRdieu Pierre (1998). La Domination masculine. Paris, Seuil.

BouRdieu Pierre (2003) [1997]. Méditations pascaliennes. Paris, Seuil.

BourdieU Pierre, Chamboredon Jean-Claude, PASSERON Jean-Claude (1968). Le Métier de sociologue. Paris, Mouton.

Bourdieu Pierre \& PASSERON Jean-Claude (1964). Les Héritiers. Les étudiants et la culture. Paris, Minuit.

BOURDIEU Pierre \& PASSERON Jean-Claude (1970). La Reproduction. Éléments pour une théorie du système d'enseignement. Paris, Minuit. BOURDIEU Pierre \& WACQUANT LOÏc (2014). Invitation à la sociologie réflexive. Paris, Seuil.
BOUTIER Jean (2008). «Quelques réflexions rétrospectives sur les histoires de la "culture populaire" ». Journée d'étude « Le Savant et le Populaire, 1989-2008. Retour sur un débat en suspens ». SHADYC, EHESS Marseille (non publié).

BOUVERESSE Jacques (2008). « Le besoin de croyance et le besoin de vérité ». Agone, 38-39: 281-306.

BuRkE Peter (1978). Popular Culture in Early Modern Europe. Londres, Temple Smith.

Buscatto Marie (2014). Sociologies du genre. Paris, Armand Colin

BusıNo Giovanni (2006). «Entretien avec Dominique Schnapper ». Revue européenne des sciences sociales, XLIV(135). [En ligne] http://ress. revues.org/271 [consulté le 12 octobre 2016].

Casanova Pascale (2008) [1999]. La République mondiale des lettres. Paris, Seuil.

ChAPOULIE Jean-Michel (1991). « La seconde fondation de la sociologie française, les États-Unis et la classe ouvrière ». Revue française de sociologie 32(3) : 321-364.

CHARTIER Roger (2001). "Culture écrite et littérature à l'âge moderne ». Annales. Histoire, Sciences sociales, 56(4) : 783-802.

COHEN Déborah (2010). La Nature du peuple. Les formes de l'imaginaire social (XVIII $/ X X I^{e}$ siècles). Seyssel, Champ Vallon.

COLLECTIF (1988). « Histoire et sciences sociales. Un tournant critique ?». Annales ESC, 2 : 291-293.

Collectif Révoltes logiques (1984). L'Empire du sociologue. Paris, La Découverte.

Collovald Annie (1988). « Identité(s) stratégiques(s) », Actes de la recherche en sciences sociales, $73: 29-40$.

Connell Raewyn (1995). Masculinities. Cambridge, Polity Press.

CoRNU Tanguy (2008). «L'ambiguïté du concept de domination symbolique dans Le Savant et le Populaire ». Journée d'étude « Le Savant et le Populaire, 1989-2008. Retour sur un débat en suspens ». SHADYC, EHESS Marseille (non publié).

Coulangeon Philippe \& DuvaL Julien (2013). Trente ans après La Distinction de Pierre Bourdieu. Paris, La Découverte.

Coulangeon, Philippe \& Duval Julien (2013). « Introduction ». In EID. (dir.), Trente ans après La Distinction de Pierre Bourdieu. Paris, La Découverte. 
Daudet Alphonse (1868). Le Petit Chose. Paris, Pierre-Jules Hetzel.

Debeauvals Michel (1976). L'Université ouverte : les dossiers de Vincennes. Grenoble, Presses Universitaires de Grenoble.

Dragomir Lucia (2011). « L'Union des écrivains. Un modèle institutionnel et ses limites ». Vingtième siècle, $109:$ 59-70.

Ducournau Claire (2017). "Les deux (ou trois) carrières de Richard Hoggart. De la fondation des cultural studies aux appropriations de la sociologie française ". Revue d'anthropologie des connaissances, 11(3) : 263-282.

Dumont Fabienne \& SofiO Séverine (2007). " Esquisse d'une épistémologie de la théorisation féministe en art ». Cahiers du genre, 43 : 17-43.

DUVAL Julien (2010). "Distinction studies ". Actes de la recherche en sciences sociales, 181-182: 146-156.

ELIAS Norbert (1991). La Société des individus. Traduit de l'allemand par Jeanna Etoré. Paris, Fayard.

FABIANI Jean-Louis (dir.) (2001). Le Goût de l'enquête. Pour Jean-Claude Passeron. Paris, L'Harmattan.

FossÉ-PolıAK Claude (2006). Aux frontières du champ littéraire. Sociologie des écrivains amateurs. Paris, Économica.

FouCAuLt Michel (1973). Moi, Pierre Rivière ayant égorgé ma mère, ma sœur et mon frère... Paris, Gallimard/Julliard.

Foucault Michel (1994). Dits et écrits, t. 1 et 2. Paris, Gallimard.

GaboriAu Philippe (1995). Le Tour de France et le vélo. Histoire sociale d'une épopée contemporaine. Paris, L'Harmattan.

GabORIAU Philippe (2003). Les Spectacles sportifs. Grandeurs et décadences. Paris, L'Harmattan.

GinZBURG Carlo (1980) [1976]. Le Fromage et les vers. L'univers d'un meunier du XVI siècle [Il formaggio e i vermi. II cosmo di un mugnaio del Cinquecento, Turin, Einaudi]. Traduit de l'italien par Monique Aymard. Paris, Flammarion.

Grenier Jean-Yves, Grignon Claude, Menger Pierre-Michel (dir.) (2001). Le Modèle et le récit. Paris, Maison des Sciences de l'Homme.

GrignON Claude (1996). « Le savant et le lettré, ou l'examen d'une désillusion », Revue européenne des sciences sociales, 103 : 81-98.
GriGNON Claude (2001). " La formalisation et les sciences du récit, le cas de la sociologie ". In Grenier Jean-Yves, Grignon Claude, Menger Pierre-Michel (dir.), Le Modèle et le récit. Paris, Maison des Sciences de l'Homme : 7-43.

GriGnON Claude \& Kordon Claude (dir.) (2009). Sciences de l'homme et sciences de la nature, essais d'épistémologie comparée. Paris, Maison des Sciences de l'Homme.

GRIGNON Claude \& PASSERON Jean-Claude (1982). Sociologie de la culture et sociologie des cultures populaires. Paris, Documents du GIDES, 4

Grignon Claude \& PAsseron Jean-Claude (1985). Enquête. Cahiers du CERCOM, 1 (« À propos des cultures populaires »). [En ligne] https:// enquete.reveues.org/2 [consulté le 26 juin 2017].

GRIGNON Claude \& PASSERON Jean-Claude (2015) [1989]. Le Savant et le Populaire. Misérabilisme et populisme en sociologie et en littérature. Paris, Seuil, «Points 》 [1 $1^{\text {re }}$ éd. Gallimard/Seuil, « Hautes études 》]. En espagnol : Grignon Claude \& PASSERON Jean-Claude (1991). Lo culto y lo popular : miserabilismo y populismo en sociologia y en literatura. Traduction de María Sonderéguer. Buenos Aires, Ediciones Nueva Vision; GrignON Claude \& PASSERON Jean-Claude (1992). Lo culto y lo popular : miserabilismo y populismo en sociologia y en literatura. Traduction de Fernando Alvarez-Uria et Julia Varela. Madrid, Las Ediciones de La Piqueta.

Grignon Claude, Collovald Annie, Pudal Bernard, Sawickı Frédéric (1991). « Un savant et le populaire. Entretien avec Claude Grignon ». Politix, $13:$ 35-42.

GRUEL Louis (2004). La Rébellion de 68. Une relecture sociologique. Rennes, Presses Universitaires de Rennes.

GUILLAUMIN Colette (2002) [1972]. L'Idéologie raciste. Paris, Gallimard.

HaLL Stuart \& JeFFERSON Tony (dir.) (1976). Resistance through Rituals : Youth Subcultures in Post-War Britain. Londres, Hutchinson.

Hammou Karim (2008). « Penser le pouvoir avec Le Savant et le Populaire». Journée d'étude « Le Savant et le Populaire, 1989-2008. Retour sur un débat en suspens ». SHADYC, EHESS Marseille (non publié).

HEINICH Nathalie (2000) [1991]. Etre écrivain. Paris, La Découverte.

Hoggart Richard (1970a). La Culture du pauvre. Étude sur le style de vie des classes populaires en Angleterre. Traduit de l'anglais par Françoise 
Garcia, Jean-Claude Garcia et Jean-Claude Passeron, présentation et index de Jean-Claude Passeron (titre original The Uses of Literacy : Aspects of Working Class Life). Paris, Minuit.

HogGART Richard (1970b). Speaking to Each Other, vol. 1. Londres, Chatto et Windus.

HogGaRT Richard (2013) [1991]. 33 Newport Street. Autobiographie d'un intellectuel issu des classes populaires anglaises. Traduit de l'anglais par Christiane Grignon \& Claude Grignon avec la collaboration de Christopher Todd, présentation de Claude Grignon. Paris, Seuil, «Points »

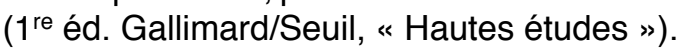

KALIFA Dominique (2005). "Les historiens français et le "populaire" ». Hermès, $42:$ 54-59.

KRÉFA Abir (2013). " La quête de l'autonomie littéraire en contexte autoritaire : le cas des écrivains tunisiens ». Sociologie, $4: 395-411$.

KRÉFA Abir (2013). Activités littéraires et rapports sociaux de sexe : le cas des écrivains tunisiens (thèse de doctorat en sociologie). Lyon, Université Lyon 2.

KRÉFA Abir (2014). « Entre injonctions à dire et à taire le corps : les voies étroites de la reconnaissance littéraire pour les écrivaines tunisiennes ". Ethnologie française, 44(4) : 631-642.

LAGRAVE Rose-Marie (1980). Le Village romanesque. Le Paradou, Actes Sud, «Espace-temps ».

LAGRAVE Rose-Marie (1988). "Mensonge romanesque et vérité des romanciers. Une relecture du Village Romanesque ». Etudes Rurales, $109: 55-73$.

LAGRAVE Rose-Marie (2009). "Filiations intellectuelles et espérance sociale. Figure et œuvre de Placide Rambaud ». Études rurales, 183 : 51-66.

LaGrave Rose-Marie (2010). "Se ressaisir ». Genre, Sexualité \& Société, $4: 1$-17. [En ligne] http://gss.revues.org

LAHIRE Bernard (2004). La Culture des individus : dissonances culturelles et distinction de soi. Paris, La Découverte.

LAHIRE Bernard (2008). La Raison scolaire. École et pratiques d'écriture, entre savoir et pouvoir. Rennes, Presses Universitaires de Rennes.

Lahire Bernard (2012). Monde pluriel. Penser l'unité des sciences sociales. Paris, La Découverte.
LAMONT Michèle (1995). La Morale et l'argent : les valeurs des cadres en France et aux États-Unis. Paris, Métailié.

LAMONT Michèle (2013). " En quoi Bourdieu a-t-il été utile à notre réflexion ? Le cas des États-Unis ». In CoulANGEON Philippe \& DuvaL Julien (dir.), Trente ans après La Distinction de Pierre Bourdieu. Paris, La Découverte : 59-68.

Levı Giovanni (1989). Le Pouvoir au village. Histoire d'un exorciste dans le Piémont du XVII siècle. Paris, Gallimard.

LINHART Robert (1981). L'Etabli. Paris, Minuit.

MACKENZIE Caroline (2012). " Agency, un mot, un engagement 》. Rives méditerranéennes, 41(1). [En ligne] http://rives.revues.org/4139 [consulté le 11 mars 2017].

MATHIEU Nicole-Claude (1991). L'Anatomie politique. Paris, Côté-Femmes. MAUGER Gérard (1991). «Enquêter en milieu populaire ». Genèses, 6 : 125-143.

MAUGER Gérard (2005). " Un apprentissage tardif du métier de sociologue ». In MAUGER Gérard (dir.), Rencontres avec Pierre Bourdieu. Bellecombe-en-Bauges, Le Croquant : 239-257.

MAUGER Gérard (2006a). « Sur la violence symbolique ». In MüLLER HansPeter \& Sintomer Yves (dir.). Pierre Bourdieu, théorie et pratique. Paris, La Découverte : 84-100.

MAUGER Gérard (2006b). Les Bandes, le milieu et la bohème populaire. Études de sociologie de la déviance des jeunes des classes populaires (1975-2005). Paris, Belin.

MAUgeR Gérard (2013). " Bourdieu et les classes populaires. L'ambivalence des cultures dominées ». In CoulangeOn Philippe \& DUVAL Julien (dir.), Trente ans après La Distinction de Pierre Bourdieu. Paris, La Découverte : 243-254.

MAUGER Gérard (2014). « Domination ». Le Lexique socius. [En ligne] http:// ressources-socius.info/index.php/lexique/21-lexique/154-domination [consulté le 14 janvier 2017].

MAUGer Gérard \& Fossé Claude (1977). La Vie buissonnière. Marginalité petite-bourgeoise et marginalité populaire. Paris, Maspero.

MAUGER Gérard \& Fossé-PolıAK Claude (1985). "Choix politiques et choix de recherches. Essai d'auto-socio-analyse (1973-1984) ». Cahiers « Jeunesses et Sociétés », 3-4-5: 27-121. 
MENGER Pierre-Michel (2009). Le Travail créateur. S'accomplir dans l'incertain. Paris, Gallimard/Seuil, « Hautes études ».

MoRRISON Toni (1990). Playing in the Dark : Whiteness and The Literary Imagination. New York, Vintage Books.

MouLIN Raymonde (1971). "La Culture du pauvre. À propos du livre de Richard Hoggart ». Revue française de sociologie, 12(2) : 255-258.

Moulin Raymonde (1992). L'Artiste, l'institution et le marché. Paris, Flammarion.

MouLIN Raymonde (dir.) (1986). Sociologie de l'art. Paris, La Documentation française.

MoULIN Raymonde, PASSERON Jean-Claude, PASQUIER Dominique, PoRTO-

VAsquez Fernando (1985). Les Artistes, essai de morphologie sociale. Paris, La Documentation Française.

NAUDIER Delphine \& ROLLET Brigitte (2007). Genre et légitimité culturelle. Quelle reconnaissance pour les femmes ?. Paris, L'Harmattan.

NAVEL Georges (1945). Travaux. Paris, Gallimard.

NeVEU Érik (1999). "Pour en finir avec l'enfantisme. Retours sur enquêtes ». Réseaux, 92-93: 175-201.

NEVEU Érik (2008). «Les voyages des cultural studies ». L'Homme, 187$188: 315-341$

NoIRIEL Gérard (1988). Le Creuset français. Histoire de l'immigration $\left(X I X^{e}-X X^{e}\right.$ siècle). Paris, Seuil.

Olivier DE SARDAN Jean-Pierre (2008). La Rigueur du qualitatif. Les contraintes empiriques de l'interprétation socio-anthropologique. Louvain, Bruylant Academia.

PARETO Vilfredo (1917). Traité de sociologie générale. Traduit de l'italien par Pierre Boven. Lausanne, Payot.

PASQUali Paul \& SchWARTZ Olivier (2016). "La Culture du pauvre : un classique revisité. Hoggart, Les classes populaires et la mobilité sociale ». Politix, 114 : 21-45.

Pasquali Paul (2014). Passer les frontières sociales. Comment les " filières d'élite " entrouvrent leurs portes. Paris, Fayard.

PASQUIER Dominique (1989). La Culture des sentiments. L'expérience télévisuelle des adolescents. Paris, Éditions de la MSH.

PASquier Dominique (2005). " La "culture populaire" à l'épreuve des débats sociologiques ». Hermès, $42:$ 60-69.
PASSERON Jean-Claude (2006) [1991]. Le Raisonnement sociologique. Un espace non poppérien de l'argumentation. Paris, Albin Michel, nouvelle édition revue et augmentée (première édition Paris, Nathan).

PAsseron Jean-Claude \& PedLeR Emmanuel (1991). Le Temps donne aux tableaux. Compte rendu d'une enquête au musée Granet. Marseille, Imerec.

PAsseron Jean-Claude \& Grumbach Michel (dir.) (1985). L'CEil à la page : enquête sur les images et les bibliothèques. Paris, Bibliothèque publique d'information, Service des études et de la recherche.

PAsSERON Jean-Claude (dir.) (1999). Richard Hoggart en France. Paris, Bibliothèque publique d'information.

Pedler Emmanuel (2010). « Les sociologies de la musique de Max Weber et Georg Simmel. Une théorie relationnelle des pratiques musiciennes ». L'Année sociologique, 60(2) : 305-330.

Pedler Emmanuel (2016). L'Esprit des lieux. Paris, Éditions de l'EHESS. Pedler Emmanuel \& Bourbonnaud David (2002a). "L'offre du festival "in" d'Avignon : effet d'imposition ou stimulation culturelle ? ». Actes du colloque d'Amiens.

Pedler Emmanuel \& Bourbonnaud David (2002b). « La programmation du Festival. Un pacte de confiance entre l'organisation festivalière et son public ». In ETHIS Emmanuel (dir.), Avignon : le public réinventé. Paris, La Documentation française : 131-159.

Pedler Emmanuel \& ZerbiB Olivier (2001). Les Nouvelles Technologies à l'épreuve des bibliothèques. Paris, Bibliothèque publique d'information. Peterson Richard A. \& Simkus Albert (1992). " How Musical Tastes Mark Occupational Status Groups ». In LAMONT Michèle \& FournIER Marcel, Cultivating differences : Symbolic Boundaries and the Making of Inequality. Chicago, The University of Chicago Press : 152-168.

Peterson Richard A. (1992). «Understanding audience segmentation : From elite and mass to omnivore and univore $»$. Poetics, 21(4) : 243-258. PETERSON Richard A. (1997). "The Rise and Fall of Highbrow Snobbery as a Status Marker ». Poetics, 25(2-3) : 75-92.

Peterson Richard A. \& Kern Roger M. (1996). "Changing Highbrow Taste : from Snob to Omnivore ». American Sociological Review, 61(5) : 900-907.

PUDAL Bernard (1991). « Le populaire à l'encan ». Politix, 13 : 53-64. 
RANCIÈRE Jacques (1981). La Nuit des prolétaires. Archives du rêve ouvrier. Paris, Fayard.

RANCIÈRE Jacques (2011). La Leçon d'Althusser. Paris, La Fabrique.

ReVEL Jacques (dir.) (1996). Jeux d'échelles. La micro-analyse à l'expérience. Paris, Gallimard/Seuil.

RoBInson Eric E. (1968). The New Polytechnics. The People's Universities. Harmondsworth, Penguin.

ROEDIGER David (1991). The Wages of Whiteness : Race and the Making of the American Working Class. New York, Verso.

SAPIRO Gisèle (2013a). "La carrière internationale de La Distinction ». In CoULANGEON Philippe \& DuvaL Julien (dir.), Trente ans après La Distinction de Pierre Bourdieu. Paris, La Découverte : 45-58.

SAPIRO Gisèle (2013b). "Le champ est-il national ? La théorie de la différenciation sociale au prisme de l'histoire globale ". Actes de la recherche en sciences sociales, $200: 70-85$.

SCHILLING Heinz (1981). Konfessionskonflikt und Staatsbildung. Eine Fallstudie über das Verhältnis von religiösem und sozialem Wandel in der Früh Neuzeit am Beispiel der Grafschaft Lippe. Gütersloh, Bertelsmann. ScotT James (2008). La Domination et les arts de la résistance. Fragments du discours subalterne. Traduction française par Olivier Ruchet. Paris, Éditions Amsterdam.

Servien Pius (1935). Principes d'esthétique. Problèmes d'art et langage des sciences. Paris, Boivin.

SINGLY François (DE) (1998). « Bourdieu : nom propre d'une entreprise collective ». Le Magazine littéraire, $369: 39-44$.

SUTTON-SMith Brian (1970). "Psychology of Childlore : The Triviality Barrier ». Western Folklore, 29(1) : 1-8.

TAINE Hyppolite (1858). Essais de critique et d'histoire. Paris, Hachette. VEYNE Paul (1971). Comment on écrit l'histoire. Essai d'épistémologie. Paris, Seuil.

VEYNE Paul (2008). Foucault. Sa pensée, sa personne. Paris, Albin Michel. WEBER Max (1998) [1921]. Sociologie de la musique. Les fondements rationnels et sociaux de la musique [Die rationalen und soziologischen Grundlagen der Musik, Tübingen, Drei Masken Verlag]. Traduit de l'allemand par Jean Molino et Emmanuel Pedler. Paris, Métailié.
Wimmer Andreas \& GLICK SCHILLER Nina (2002). « Methodological Nationalism and Beyond : Nation-State Building, Migration and the Socia Sciences ». Global Network, 2 : 301-334. 